\title{
Effect of the queen on worker reproduction and new queen production in the bumble bee Bombus terrestris*
}

\author{
Carlos LOPEZ-VAAMONDE ${ }^{\mathrm{a}, \mathrm{b}}$, Ruth M. BROWN ${ }^{\mathrm{a}}$, Eric R. LUCAS ${ }^{\mathrm{a}, \mathrm{c}}$, \\ Jeffrey J.M. PEREBOOM ${ }^{\mathrm{a}, \mathrm{d}}$, William C. JORDAN ${ }^{\mathrm{a}}$, Andrew F.G. BOURKE ${ }^{\mathrm{a}, \mathrm{e}}$ \\ ${ }^{\text {a }}$ Institute of Zoology, Zoological Society of London, Regent's Park, London NW1 4RY, UK \\ ${ }^{\mathrm{b}}$ INRA-Orléans, Laboratoire de Zoologie Forestière, BP 20619, Ardon, 45166 Olivet Cedex, France \\ ${ }^{c}$ Department of Biology, University College London, Wolfson House, 4 Stephenson Way, London NW1 2HE, \\ UK \\ ${ }^{\mathrm{d}}$ Centre for Research and Conservation, Royal Zoological Society of Antwerp, Koningin Astridplein 26, 2018 \\ Antwerp, Belgium \\ ${ }^{\mathrm{e}}$ School of Biological Sciences, University of East Anglia, Norwich NR4 7TJ, UK
}

Received 23 May 2006 - Revised 18 August 2006 - Accepted 21 August 2006

\begin{abstract}
We tested the hypotheses that a non-volatile pheromone inhibiting worker egg-laying and queen development produced by Bombus terrestris queens has effects transferable (a) from workers to other workers or larvae, or (b) on wax. We subdivided small, young colonies with a single mesh screen (Experiment 1) and larger, older colonies with a double mesh screen (Experiment 2). One treatment (in both experiments) involved the transfer of workers, and one treatment (in Experiment 2 only) involved the transfer of wax, from the queenright to the queenless compartments. Queenlessness induced significantly earlier onset of worker aggression (followed by egg-laying) in all treatments in both experiments, and significantly earlier queen production in all treatments in Experiment 2 (small colony sizes probably hindered queen production in Experiment 1). These findings suggested that the effects of $B$. terrestris queen pheromone are not transferable via workers or wax.
\end{abstract}

Bombus / caste determination / pheromone / queen signal / worker reproduction

\section{INTRODUCTION}

The mechanisms by which queens in social insects regulate reproduction within the colony represent a topic of major interest in the biology of social insects (e.g. Endler et al., 2004). In the bumble bee Bombus terrestris L., colonies reach a point (the competition point) at which the workers commence aggression and egg-laying and following which the first new queens eventually eclose (Duchateau and Velthuis, 1988; Bloch, 1999). There is a tight temporal link between the onset of

Corresponding author: A.F.G. Bourke,

a.bourke@uea.ac.uk

* Manuscript editor: Stan Schneider worker reproduction and queen production, with the competition point predictably occurring c. 10 days after the queen lays the first diploid eggs that will develop as new queens (Duchateau and Velthuis, 1988; Bloch, 1999; Bortolotti et al., 2001; Alaux et al., 2004). A variety of evidence supports pheromonal queen regulation of worker reproduction and queen development, but the exact mechanisms are not fully resolved (Crespi, 1992; Kukuk, 1992; Bloch and Hefetz, 1999a; Cnaani et al., 2000; Bourke and Ratnieks, 2001; Duchateau et al., 2004), partly because the experimental evidence is not always consistent across different studies. With this qualification, the evidence suggests that, before the competition point, workers refrain from egg-laying 
because they are exposed to a non-volatile pheromone borne on the queen's cuticle. After the competition point, either the queen ceases pheromone production, or workers cease to respond to the pheromone (Bloch et al., 1996; Bloch and Hefetz, 1999a,b; Alaux et al., 2004, 2006). Similarly, evidence suggests that, before the competition point, early-instar (i.e. bipotent) female larvae refrain from commencing development as queens because they are exposed to a non-volatile pheromone produced by the queen. After the competition point, either the queen ceases pheromone production, or the larvae cease to respond to the queen's pheromone (Röseler, 1970, 1991; Cnaani et al., 1997, 2000; Ribeiro et al., 1999; Pereboom, 2000).

As part of this overall scheme, an additional mechanism was suggested by a pioneering experiment conducted by Röseler (1970). Röseler (1970) split B. terrestris colonies with a single mesh screen and found that female larvae on the queenless side developed as queens, unless workers could cross (when the screen was coarse) to the queenless side or workers were regularly (every $24 \mathrm{~h}$ ) exchanged between the queenright and queenless sides. This suggested that a non-volatile queen pheromone preventing the development of female larvae as queens either alters the workers' treatment of female larvae (Röseler, 1970, 1991) or, after workers' direct or indirect contact with the queen, is distributed by the workers to the larvae and acts on larvae directly. However, subsequent evidence, e.g. the finding that the composition of food fed by workers to larvae does not differ before and after the competition point, has not supported the first possibility (Pereboom, 2000; Pereboom et al., 2003).

Alaux et al. (2004) recently carried out similar split-colony experiments to those of Röseler (1970) to test for queen effects on worker reproduction in $B$. terrestris. In their Experiment (c), Alaux et al. (2004) prevented callow workers from passing through a screen separating them from the queen (by wire glued to their thoraces). They found that these workers laid eggs significantly earlier than queenright workers, so showing that those workers that could still pass through the screen did not transfer pheromone from the queen inhibiting egg-laying by the wire-attached workers. From their other experiments, Alaux et al. (2004) concluded that the queen pheromone is not volatile, that it is not borne on a mixture of larvae, cocoons and wax, and that workers require regular contact with the queen to remain reproductively inhibited.

In the present study, we extended and partially repeated the experiments of Röseler (1970) and Alaux et al. (2004) to test two hypotheses. The first (Hypothesis 1a) was that the queen produces non-volatile pheromone(s) in the absence of which adult workers commence egg-laying and early-instar female larvae initiate development as queens, with the effect of the pheromone(s) being transferable from workers to other workers or to larvae. The second (Hypothesis $1 \mathrm{~b}$, which was prompted by our failure to confirm Hypothesis 1a) was the same as Hypothesis 1a except that we hypothesized the pheromone(s) to be borne on wax (excluding larvae and cocoons) present in the nest (cf. the honey bee, Apis mellifera: Naumann et al., 1991). Our study is novel in that we explicitly sought to investigate the mechanism of queen regulation of reproduction with respect to worker reproduction and queen development simultaneously. Overall, despite differences in experimental design between all three studies, our results (see Discussion) proved congruent with those of Alaux et al. (2004) but not with all of those of Röseler (1970).

\section{MATERIALS AND METHODS}

\subsection{Experiment 1}

\subsubsection{Bumblebee rearing}

To test Hypothesis 1a, we obtained 26 B. terrestris colonies from a commercial supplier (Koppert Biological Systems, Berkel en Rodenrijs, Netherlands). On receipt, we transferred each colony to a wooden nest-box $(20 \times 30 \mathrm{~cm}$ and $17 \mathrm{~cm}$ high), with a clear Perspex lid. The nest-boxes had internal vertical slots fitted mid-way along each of the longer walls for placement of screens. All colonies were kept under red light at $28{ }^{\circ} \mathrm{C}$ and $60 \%$ relative humidity. Each day, we provided thawed pollen (supplied fresh by Koppert Biological Systems and frozen by us on receipt) and the same 
supplier's sugar solution, except after Day 27 after colony splitting when dried pollen was provided owing to a lack of fresh pollen. Food was placed directly on the nest-box floor, with each compartment of split colonies receiving an equal amount.

\subsubsection{Splitting of experimental colonies}

On arrival, all 26 colonies contained a queen and a mean ( \pm S.D.) of $10.5 \pm 3.0$ workers and were therefore aged an estimated 7-10 days since first worker emergence. We randomly allocated 10, 8 and 8 of the colonies, respectively, to one of three treatments (Treatments 1a-c; Tab. I). For each treatment, on the day colonies were received (16 April 2004), we used a single screen of fine wire mesh to divide each colony (worker population, brood and nest structure) into two equal or nearly-equal portions (QRC, queenright compartment, to which the queen was confined, and QLC, queenless compartment). Adult bees in the two compartments could have only antennal contact through the screen.

\subsubsection{Monitoring of experimental colonies}

Simultaneously with the splitting of the colonies, all adult workers were marked on the thorax with water-based paint ('Posterman' paint pen, Kuretake Co. Ltd, Japan). To distinguish workers when transferred between compartments (see below), workers in QRCs were marked yellow and those in QLCs were marked white. Newly-eclosed workers were marked (yellow or white according to their compartment type) on a daily basis. Once the colonies were split, we simultaneously observed both the QRC and QLC of each colony for bouts of $15 \mathrm{~min}$. per colony per day until the end of the experiment. In each type of compartment, we defined the competition point as occurring when the first worker aggression was observed (cf. Lopez-Vaamonde et al., 2003) and we measured the onset of queen production by recording the date on which the first queen larva was observed, based on larval size (Cnaani et al., 1997). Newly-eclosed sexuals were removed daily as callows.

\subsubsection{Experimental treatments}

Treatment 1a involved splitting each colony without further manipulation (Tab. I). Treatment $1 \mathrm{~b}$ involved, following colony splitting, the transfer of workers from the QRC to the corresponding
QLC. On Day 2 after colony splitting, we randomly chose $50 \%$ of the workers in the QRC and placed them in the QLC. After $24 \mathrm{~h}$ we transferred them into a 'holding container' (they were identifiable from their yellow paint marks) and then immediately transferred all workers in the QRC (i.e. the remaining $50 \%$ of QRC workers not transferred $24 \mathrm{~h}$ previously) to the QLC. The workers in the holding container were then replaced in the QRC. We repeated this process every $24 \mathrm{~h}$. This procedure ensured that workers transferred from the QRC to the QLC always consisted entirely of workers that had been in the QRC (and hence in contact with the queen) for the previous $24 \mathrm{~h}$. It also ensured that workers initially in the QLC, or that eclosed in it, were constantly exposed to workers from the QRC but were never themselves transferred to the QRC and hence never had contact with the queen. In Treatment $1 \mathrm{~b}$, we recorded the competition point in QLCs based on the behaviour of only those workers that were initially in QLCs or that had eclosed in them (i.e. those workers permanently separated from the queen, identifiable from their white paint marks). We ended the transfer of workers when each QRC reached its competition point.

Treatment $1 \mathrm{c}$ represented a 'sham-transfer' control for Treatment $1 \mathrm{~b}$. Every $24 \mathrm{~h}$ following the colony split, we randomly chose $50 \%$ of the workers in the QRC, transferred them to the QLC and immediately returned them to the QRC. We again stopped this procedure when each QRC reached its competition point.

The experiment was terminated on Day 36 after colonies were split, since $B$. terrestris queens take a maximum of 34 days to develop from egg to adult (Bloch, 1999). Final numbers of adult workers and queens were counted in all colonies (counts for QLCs in Treatment 1b excluded workers transferred from the QRCs, which were included in the QRC counts).

\subsection{Experiment 2}

\subsubsection{Experimental set-up}

The purpose of this Experiment was (i) to repeat Experiment 1 and (ii) to test Hypothesis 1b. The results of Experiment 1 did not fully match the predictions of Hypothesis 1a. One way in which this was the case was that no or very few new queens were produced in any treatment (Tab. I). Because queen production is a characteristic of large, mature colonies (Duchateau and Velthuis, 1989; Beekman 
Table I. Summary of design of split-colony experiments in Bombus terrestris, predictions (from Hypotheses $1 \mathrm{a}$ and $1 \mathrm{~b}$ ) for each treatment, and results. $\mathrm{QRC}=$ queenright compartment, $\mathrm{QLC}=$ Queenless compartment.

\begin{tabular}{|c|c|c|}
\hline Treatment & Prediction & Results match prediction? \\
\hline
\end{tabular}

\section{Experiment 1}

1a. Colony split with single screen Competition point and queen production ( $\mathrm{n}=10$ colonies).

1b. Colony split with single screen, plus worker transfer $(\mathrm{n}=8$ colonies).

1c. Colony split with single screen, plus sham worker transfer (control for $1 \mathrm{~b})$ ( $\mathrm{n}=8$ colonies).

Experiment 2 (all $\mathrm{n}=6$ colonies)

2a. Colony split with double screen.

2b. Colony split with double screen, plus worker transfer.

2c. Colony split with double screen, plus sham worker transfer (control for $2 b$ ).

2d. Colony split with double screen, plus wax transferred from QRC to QLC.

2e. Colony split with double screen, plus wax transferred from queen-producing colonies to QLC (control for $2 \mathrm{~d}$ ). should start earlier in QLC than in QRC.

Competition point and queen production should start at same time in QLC as in QRC.

As for Treatment 1a.

Competition point and queen production should start earlier in QLC than in QRC.

Competition point and queen production should start at same time in QLC as in QRC.

As for Treatment $2 \mathrm{a}$.

As for Treatment $2 \mathrm{~b}$

Yes

Yes

No: QLC earlier No: QLC earlier than QRC than QRC

Yes

Yes

As for Treatment $2 \mathrm{a}$
No: no queen

larvae produced

No*: QLC

earlier than

QRC

No: no queen

larvae produced

* Trend in stated direction but not statistically analysable because of small sample size.

and Van Stratum, 1998; Bloch, 1999), we therefore repeated Experiment 1 using colonies of greater initial size and age. In case the lack of queen production in QLCs was due to the change from fresh to dry pollen and/or the transfer of queen pheromone via worker antennal contact through the mesh, we also provided fresh pollen throughout the experiment and used a double screen of mesh with the screens $8 \mathrm{~mm}$ apart (so preventing adult bees from having any physical contact across compartments).

\subsubsection{Experimental treatments}

Housing, colony splitting (apart from the use of a double screen), worker marking and colony mon- itoring were all as for Experiment 1. We obtained 34 colonies from Koppert Biological Systems on 30 June 2004. On arrival, four colonies had begun queen production (queen larvae and pupae both present) and were therefore selected as sources of wax for Treatment 2e (Tab. I). The 30 remaining colonies contained a queen and a mean $( \pm$ S.D.) of $26.4 \pm 9.6$ workers (i.e. were over twice as large as the colonies in Experiment 1, with an estimated age from first worker emergence of 10-14 days). As expected in colonies of this size (unpublished observations), none had reached the competition point.

Twenty-four hours after their arrival, we randomly allocated 6 of the 30 experimental colonies to each of 5 treatments (Treatments $2 \mathrm{a}-\mathrm{e}$; Tab. I). 
Treatment 2a involved splitting each colony without further manipulation. Treatments $2 \mathrm{~b}$ and $2 \mathrm{c}$ involved, respectively, the transfer or sham-transfer of workers from the QRC to the QLC as per Treatments $1 \mathrm{~b}$ and $1 \mathrm{c}$. In Treatment $2 \mathrm{~d}$ we tested Hypothesis $1 \mathrm{~b}$ by, once a day, transferring a piece of wax (approximately $0.3 \mathrm{~g}$, taken from the nest edge) from the QRC to the corresponding QLC. In Treatment $2 \mathrm{e}$ (control for $2 \mathrm{~d}$, i.e. for any mechanical effects of adding wax), we daily added to the QLC approximately $0.3 \mathrm{~g}$ of wax from the four mature source colonies that had already commenced queen production (see above). In both treatments, we stopped adding wax to the QLC when the QRC reached the competition point (Tab. II). On average, therefore, each QLC received an approximate total of $4.3 \mathrm{~g}$ of wax in Treatment $2 \mathrm{~d}$ and $3.6 \mathrm{~g}$ of wax in Treatment 2e.

\section{RESULTS}

\subsection{Experiment 1}

\subsubsection{Final colony sizes}

The mean $( \pm$ S.D.) numbers of workers per colony at the end of the experiment were as follows: Treatment 1a: QRC, $121 \pm 31$; QLC, $55 \pm 17 ; \mathrm{n}=10$ colonies; Treatment $1 \mathrm{~b}$ : QRC, $62 \pm 19$; QLC, $59 \pm 12 ; \mathrm{n}=8$ colonies; Treatment 1c: QRC, $120 \pm 54$; QLC, $58 \pm 19$; $\mathrm{n}=$ 8 colonies.

\subsubsection{Timing of competition point}

QLCs of every colony reached the competition point earlier than QRCs, shortly after the colony split, and there was no significant difference across treatments in the withintreatment interval in days between the competition point in QRCs and the competition point in QLCs (Kruskal-Wallis test: $\mathrm{H}=0.66$, d.f. $=2, P>0.7$; Tab. II). Pooling across treatments, we found that QLCs reached the competition point significantly earlier than QRCs (Wilcoxon signed ranks test: $\mathrm{W}=153.0$, $\mathrm{n}=17, P<0.001)$. In QLCs, the competition point was followed $5.8 \pm 1.0$ S.D. $(n=26$ colonies) days later by the first observed instance of worker egg-laying. The earlier competition point in Treatment $1 \mathrm{~b}$ was contrary to Hypothesis 1a (Tab. I).
Table II. Timing of competition point (mean \pm S.D. days after splitting on which first worker aggression observed) in queenright and queenless compartments of Bombus terrestris colonies. In Experiment 1 , sample sizes are less than the number of colonies per treatment because in some colonies the queenright compartments had not reached the competition point before the termination of the experiment on Day 36. The timing of the competition point in queenless compartments of these omitted colonies was almost identical to that of the tabulated colonies (Treatment 1a, $2.8 \pm 0.8$ days, $\mathrm{n}=5$; $1 \mathrm{~b}, 2.0 \pm 0.0$ days, $\mathrm{n}=2$; $1 \mathrm{c}, 2.5 \pm 0.7$ days, $\mathrm{n}=2$ ).

\begin{tabular}{lccc}
\hline Treatment & $\begin{array}{c}\text { Queenright } \\
\text { compartment }\end{array}$ & $\begin{array}{c}\text { Queenless } \\
\text { compartment }\end{array}$ & $\begin{array}{c}\mathrm{n} \\
\text { colonies }\end{array}$ \\
\hline Experiment 1 & & & \\
$1 \mathrm{a}$ & $30.0 \pm 4.9$ & $2.8 \pm 1.1$ & 5 \\
$1 \mathrm{~b}$ & $27.8 \pm 6.6$ & $3.0 \pm 0.9$ & 6 \\
1c & $27.5 \pm 4.4$ & $2.7 \pm 0.8$ & 6 \\
Experiment 2 & & & \\
2a & $13.3 \pm 4.7$ & $1.7 \pm 1.0$ & 6 \\
2b & $11.3 \pm 3.8$ & $1.0 \pm 0.0$ & 6 \\
2c & $13.0 \pm 4.7$ & $0.2 \pm 0.4$ & 6 \\
2d & $14.3 \pm 1.9$ & $0.3 \pm 0.5$ & 6 \\
2e & $12.0 \pm 6.3$ & $0.5 \pm 0.5$ & 6 \\
\hline
\end{tabular}

\subsubsection{Timing of queen production}

QLCs across all treatments produced very few queens, with none eclosing before the end of the experiment (Tab. III). As a result, in Treatments 1a and 1c, there were no colonies in which queen larvae were recorded in both the QRC and the QLC (Tab. III). In Treatment $1 \mathrm{~b}$, there were two such colonies and, in both, the first queen larva was recorded earlier in the QLC than in the QRC (Tab. III). The small sample sizes precluded statistical analysis, but both the lack of queen larvae in QLCs in Treatments $1 \mathrm{a}$ and $1 \mathrm{c}$, and the earlier appearance of queen larvae in QLCs in two colonies in Treatment $1 b$, were contrary to the predictions of Hypothesis 1a (Tab. I).

\subsection{Experiment 2}

\subsubsection{Final colony sizes}

The mean ( \pm S.D.) numbers of workers per colony at the end of the experiment were as 
Table III. Timing of onset of queen production (mean \pm S.D. days after splitting on which first queen larva observed) and number of adult queens (mean \pm S.D.) eclosing before Day 36 in queenright and queenless compartments of Bombus terrestris colonies. Sample sizes are less than the number of colonies per treatment because in some colonies no queen larvae were recorded in one or both compartments before the termination of the experiment on Day 36. This was true of all colonies in Treatments 1a and 1c.

\begin{tabular}{lccccc}
\hline Treatment & \multicolumn{2}{c}{ Days to first queen larva } & \multicolumn{2}{c}{ Number of adult queens } & n colonies \\
\cline { 2 - 4 } & $\begin{array}{c}\text { Queenright } \\
\text { compartment }\end{array}$ & $\begin{array}{c}\text { Queenless } \\
\text { compartment }\end{array}$ & $\begin{array}{c}\text { Queenright } \\
\text { compartment }\end{array}$ & $\begin{array}{c}\text { Queenless } \\
\text { compartment }\end{array}$ & \\
\hline Experiment 1 & & & & & \\
1a & - & - & 0 & 0 & 10 \\
1b & $29.7 \pm 4.5$ & $12.0 \pm 5.7$ & 0 & 0 & 2 \\
1c & - & - & 0 & 0 & 8 \\
Experiment 2 & & & & & \\
2a & $14.7 \pm 3.2$ & $11.0 \pm 0.8$ & $52.8 \pm 33.4$ & $15.2 \pm 15.6$ & 4 \\
2b & $16.2 \pm 5.4$ & $10.8 \pm 3.1$ & $51.8 \pm 39.0$ & $51.0 \pm 42.7$ & 5 \\
2c & $17.7 \pm 4.3$ & $9.5 \pm 1.0$ & $36.7 \pm 27.9$ & $40.2 \pm 34.8$ & 4 \\
2d & $17.3 \pm 1.3$ & $12.5 \pm 1.3$ & $26.8 \pm 21.6$ & $11.4 \pm 12.6$ & 4 \\
2e & $25.2 \pm 6.9$ & $11.5 \pm 0.6$ & $16.7 \pm 35.7$ & $18.7 \pm 24.8$ & 4 \\
\hline
\end{tabular}

follows: Treatment 2a: QRC, $120 \pm 63$; QLC, $97 \pm 20$; Treatment 2b: QRC, $116 \pm 9$; QLC, $93 \pm 21$; Treatment 2c: QRC, $144 \pm 37$; QLC, $84 \pm 15$; Treatment 2d: QRC, $152 \pm 68$; QLC, $111 \pm 44$; Treatment 2e: QRC, $169 \pm 60 ;$ QLC, $90 \pm 23$; all $n=6$ colonies.

\subsubsection{Timing of competition point}

QLCs of every colony reached the competition point earlier than QRCs, shortly after the colony split, and there was no significant difference across treatments in the withintreatment interval in days between the competition point in QRCs and the competition point in QLCs (Kruskal-Wallis test: $\mathrm{H}=2.24$, d.f. $=4, P>0.6$; Tab. II). Pooling across treatments, we found that QLCs reached the competition point significantly earlier than the QRCs (Wilcoxon signed ranks test: $\mathrm{W}=$ 465.0, $\mathrm{n}=30, P<0.001)$. In QLCs, the competition point was followed $4.5 \pm 1.3$ S.D. days later $(\mathrm{n}=28$ colonies, since in 2 colonies no worker egg-laying was observed in at least one compartment) by the first observed instance of worker egg-laying. The earlier onset of the competition point in QLCs in Treatments 2a$\mathrm{c}$ matched the findings of Experiment 1 . In Treatments $2 b$ and $2 d$, the earlier onset of the competition point was contrary to Hypotheses $1 \mathrm{a}$ and $1 \mathrm{~b}$, respectively (Tab. I).

\subsubsection{Timing of queen production}

The first queen larva was recorded earlier in QLCs than in QRCs in all colonies except one, and, across treatments, there was no significant difference in the within-treatment interval in days between the date the first queen larva appeared in QRCs and the date the first queen larva appeared in QLCs (Kruskal-Wallis test: $\mathrm{H}=5.34$, d.f. $=4, P>0.2$; Tab. III) (The exceptional colony was in Treatment $2 \mathrm{~b}$, in which the first queen larva appeared in the QRC one day earlier than in the QLC.) Pooling across treatments, we found that the first queen larva appeared in QLCs significantly earlier than in QRCs (Wilcoxon signed ranks test: $\mathrm{W}=208.5, \mathrm{n}=20, P<0.001)$. In both types of compartment, counts of adult queens eclosing before Day 36 confirmed that appearance of queen larvae indicated subsequent 
adult queen production (Tab. III). In Treatments $2 b$ and $2 d$, the earlier onset of queen production in QLCs was contrary to Hypotheses $1 \mathrm{a}$ and $1 \mathrm{~b}$, respectively (Tab. I).

\section{DISCUSSION}

By experimentally splitting colonies of the bumble bee, Bombus terrestris, we found that partial physical separation of workers (i.e. separation allowing antennal contact) from the colony queen and from queenright workers using a mesh screen led to a significantly earlier onset of aggression (followed by egg-laying) among queenless workers (Experiment 1). We also found that complete physical separation of workers (using two parallel mesh screens preventing antennal contact) from the colony queen and from queenright workers led to the same result (Experiment 2). Both sets of findings showed that the queen's inhibitory effect on worker reproduction in intact colonies does not stem from a volatile pheromone. This conclusion matches those of previous authors (Bloch and Hefetz, 1999b; Alaux et al., 2004). In both experiments we found that transferring either workers or wax from the queenright to the queenless compartments of colonies did not restore the queen's inhibition of worker reproduction. Consistent with the conclusions of Alaux et al. (2004), these findings failed to support the idea that the non-volatile queen pheromone inhibiting worker reproduction has effects that are transferable via workers (Hypothesis 1a) or wax (Hypothesis 1b) .

We also found that physical separation of early-instar female larvae from the queen and from queenright workers did not lead to these larvae developing as queens earlier than queenright larvae in Experiment 1 (single screen, small colonies), but did lead to these larvae developing as queens significantly earlier than queenright larvae in Experiment 2 (double screen, larger colonies). If we assume that colony immaturity and/or small size independently inhibit development of larvae as queens (see below), these findings were consistent with the queen's inhibitory effect on queen development (before the competition point) not stemming from a volatile pheromone. This conclusion again matches those of previous authors (e.g. Röseler, 1970). However, in Experiment 2, neither the transfer of workers or of wax from the queenright to the queenless compartments of colonies prevented the earlier development of female larvae as queens. We therefore found no evidence that the non-volatile queen pheromone inhibiting queen development has effects that are transferable via workers (Hypothesis 1a, cf. the similar hypothesis of Röseler (1970)) or wax (Hypothesis 1b).

Conceivably, both Hypotheses $1 \mathrm{a}$ and $1 \mathrm{~b}$ are correct but features of our experimental design led to our detecting no inhibitory effect of transferring either workers or wax from the queenright to the queenless compartments on either worker reproduction or queen development. First, as regards worker transfer, the addition of workers to the queenless compartments caused the density of workers to be always greater in these compartments than in the queenright compartments. Bloch (1999) found that doubling worker number in $B$. terrestris led to a significantly earlier competition point and a significantly earlier onset of queen production relative to controls. Therefore, it is arguable that, in Treatments $1 b$ and $2 b$, the hypothesized effect of queen pheromone putatively transferred on the workers in delaying the competition point and queen production was counter-acted by higher worker density causing these events to occur earlier. However, this is unlikely for several reasons. One is that the reduction in worker numbers in the queenright compartments of Treatments $1 \mathrm{~b}$ (relative to those of Treatments $1 \mathrm{a}$ and $1 \mathrm{c}$ ), and in the queenright compartments of Treatment $2 b$ (relative to those of Treatments $2 \mathrm{a}, \mathrm{c}, \mathrm{d}$ and e), did not lead to differences in the timing of either the competition point or queen production (Tabs. II, III). This suggested that the timings of these events were unaffected by the changes in worker density experienced. Another reason is that the effects recorded by Bloch (1999), even if present, do not appear large enough to have accounted for the earlier timings of the competition point and queen production in Treatments $1 b$ and $2 b$. Finally, recent work suggests that queen age is a more important proximate determinant of the onset of queen 
production than worker number (Alaux et al., 2005).

A second possible feature leading to our not finding any effects of transferring either workers or wax from queenright to queenless compartments is that, in our experiments, too few workers, or insufficient amounts of wax, were introduced to the queenless compartments, leading to insufficient pheromone being transferred. Although we cannot formally exclude this possibility, it seems unlikely, especially as regards worker transfer (since we always transferred $50 \%$ of workers from the queenright to queenless compartments).

In Experiment 2, we found that, in the queenless compartments, workers commenced aggression and egg-laying over the same period as female larvae commenced development as queens (Tabs. II, III). This was consistent with the observed temporal link between the timing of queen production and the competition point in B. terrestris (Duchateau and Velthuis, 1988; Bloch, 1999; Bortolotti et al., 2001; Alaux et al., 2004) and, specifically, with the proposal that workers use the onset of queen development as a cue to commence egglaying (Crespi, 1992; Kukuk, 1992; Cnaani et al., 2000; Bourke and Ratnieks, 2001; Duchateau et al., 2004; Alaux et al., 2006). However, we also found that, in most colonies in Experiment 1, workers in the queenless compartments exhibited aggression and egglaying even though no new queens were developing (Tabs. II, III), so demonstrating that worker reproduction can be decoupled from the onset of queen production. This matches previous authors' findings that colonies producing no new queens exhibit a competition point (Duchateau and Velthuis, 1988) and that groups of queenless workers kept without brood activate their ovaries and lay eggs (Duchateau and Velthuis, 1989; Bloch et al., 1996; Bloch and Hefetz, 1999a).

In conclusion, although the current evidence remains that, in $B$. terrestris, a nonvolatile queen pheromone inhibits both worker egg-laying behaviour and the development of new queens (references in Introduction; present study), the mechanism by which the effects of pheromone are delivered from the queen to workers and young larvae remains to be determined. The findings of Alaux et al. (2004) and ourselves suggest that distribution of pheromone via workers or wax is unlikely. With respect to egg-laying behaviour, it is possible that workers must regularly physically contact the queen to perceive her presence and for their behaviour to be modified accordingly (Alaux et al., 2004, 2006). Detection by workers of the queen via the ongoing presence of queen-laid eggs is another possibility (cf. Endler et al., 2004). It is also probable that transfer among workers of queen pheromones would be less likely in social insects such as $B$. terrestris that have small colonies, unlike the case of the largecolony honey bee, in which worker-to-worker transfer of pheromones signaling the queen's presence occurs (Seeley, 1985). Regarding queen production in $B$. terrestris, we found that small, immature colonies responded differently to queenlessness compared to larger, more mature colonies, suggesting that the social context affects the response of $B$. terrestris adults and larvae to experimental manipulations (cf. Bloch, 1999; Bourke and Ratnieks, 2001; Alaux et al., 2005). This factor could underlie some of the inconsistencies in results from different experimental studies on $B$. terrestris (see Introduction) and will require bearing in mind in the design of future experiments to unravel the proximate regulation of reproduction in this species.

\section{ACKNOWLEDGEMENTS}

We thank Oscar Rodriguez Ramos and Will Koning for technical help and Tracey Chapman for statistical advice. This work was funded by a NERC Research Grant to A. F. G. B and W. C. J.

Action de la reine sur la reproduction des ouvrières et la production des nouvelles reines chez le bourdon Bombus terrestris.

\section{Bombus / déterminisme de la caste / phéromone / signal royal / reproduction des ouvrières}

Zusammenfassung - Auswirkungen der Königin auf die Reproduktion von Arbeiterinnen und neuen Königinnen bei der Hummel Bombus terrestris. Es gibt deutliche Hinweise, dass die 
Königinnen der Hummel Bombus terrestris L. sowohl die Eilage von Arbeiterinnen als auch die Entwicklung von weiblichen Larven zu neuen Königinnen mittels eines oder mehrerer nichtflüchtiger Pheromone hemmen. Diese Hemmung endet mit oder in etwa mit dem 'Kompetitionspunkt', an dem die Arbeiterinnen mit Aggression und Eilage beginnen und nach dem weibliche Larven sich zu Königinnen entwickeln. Unter Verwendung von geteilten Völkern testeten wir zwei Hypothesen. Die erste war, dass die Auswirkungen der Königinnenpheromone von Arbeiterinnen auf andere Arbeiterinnen oder Larven übertragen werden können. Die zweite war, dass diese auf Wachs übertragen werden können. Wir verglichen die Zeit des Kompetitionspunktes (definiert als den Beginn der Arbeiterinnenaggressivität, der von Eilage gefolgt wird) und die Produktion von Königinnen zwischen den weiselrichtigen und weisellosen Abteilen von durch ein einfaches Gitter unterteilten kleinen jungen Völkern (Experiment 1) und von mit einem doppelten Gitter unterteilten großen älteren Völkern (Experiment 2). In beiden Experimenten wurden in einer der Versuchsgruppen Arbeiterinnen von den weiselrichtigen in die weisellose Abteilung übertragen. In dem zweiten Experiment wurde zusätzlich in einer der Versuchsgruppen Wachs übertragen. Allerdings fanden wir, dass bei Weisellosigkeit der Kompetitionspunkt wesentlich früher erreicht wurde, und (außer in Experiment 1, in dem in weisellosen Völkern keine oder nur sehr wenige Königinnen erzeugt wurden) dass der Beginn der Königinnenproduktion signifikant früher war, völlig unabhängig davon ob Arbeiterinnen oder Wachs übertragen worden waren (Tab. II und III). Daher ist es unwahrscheinlich, dass Königinnenpheromon oder Pheromone über Arbeiterinnen oder Wachs verteilt werden, und es bleibt eine offene Frage, durch welchen Mechanismus der Effekt der Pheromone von der Königin zu den Arbeiterinnen oder Larven gelangt. Darüber hinaus hing in Bezug auf die Königinnenproduktion der Einfluss der Weisellosigkeit von der Koloniegröße und Reife ab, was einen Einfluss des Sozialkontext auf die Reaktion von B. terrestris auf die Experimentalbedingungen belegt.

Bombus / Kastendetermination / Pheromone / Königinnensignal / Arbeiterinnenreproduktion

\section{REFERENCES}

Alaux C., Jaisson P., Hefetz A. (2004) Queen influence on worker reproduction in bumblebees (Bombus terrestris) colonies, Insect. Soc. 51, 287-293.

Alaux C., Jaisson P., Hefetz A. (2005) Reproductive decision-making in semelparous colonies of the bumblebee Bombus terrestris, Behav. Ecol. Sociobiol. 59, 270-277.
Alaux C., Jaisson P., Hefetz A. (2006) Regulation of worker reproduction in bumblebees (Bombus terrestris): workers eavesdrop on a queen signal, Behav. Ecol. Sociobiol. 60, 439-446.

Beekman M., Van Stratum P. (1998) Bumblebee sex ratios: why do bumblebees produce so many males? Proc. R. Soc. Lond. B 265, 1535-1543.

Bloch G. (1999) Regulation of queen-worker conflict in bumble-bee (Bombus terrestris) colonies, Proc. R. Soc. Lond. B 266, 2465-2469.

Bloch G., Hefetz A. (1999a) Regulation of reproduction by dominant workers in bumblebee (Bombus terrestris) queenright colonies, Behav. Ecol. Sociobiol. 45, 125-135.

Bloch G., Hefetz A. (1999b) Reevaluation of the role of mandibular glands in regulation of reproduction in bumblebee colonies, J. Chem. Ecol. 25, 881896.

Bloch G., Borst D.W., Huang Z.-Y., Robinson G.E., Hefetz A. (1996) Effects of social conditions on Juvenile Hormone mediated reproductive development in Bombus terrestris workers, Physiol. Entomol. 21, 257-267.

Bortolotti L., Duchateau M.J., Sbrenna G. (2001) Effect of juvenile hormone on caste determination and colony processes in the bumblebee Bombus terrestris, Entomol. Exp. Appl. 101, 143-158.

Bourke A.F.G., Ratnieks F.L.W. (2001) Kin-selected conflict in the bumble-bee Bombus terrestris (Hymenoptera: Apidae), Proc. R. Soc. Lond. B 268, 347-355.

Cnaani J., Borst D.W., Huang Z.Y., Robinson G.E., Hefetz A. (1997) Caste determination in Bombus terrestris: differences in development and rates of $\mathrm{JH}$ biosynthesis between queen and worker larvae, J. Insect Physiol. 43, 373-381.

Cnaani J., Robinson G.E., Bloch G., Borst D., Hefetz A. (2000) The effect of queen-worker conflict on caste determination in the bumblebee Bombus terrestris, Behav. Ecol. Sociobiol. 47, 346-352.

Crespi B.J. (1992) Cannibalism and trophic eggs in subsocial and eusocial insects, in: Elgar M.A., Crespi B.J. (Eds.), Cannibalism: ecology and evolution among diverse taxa, Oxford University Press, Oxford, pp. 176-213.

Duchateau M.J., Velthuis H.H.W. (1988) Development and reproductive strategies in Bombus terrestris colonies, Behaviour 107, 186-207.

Duchateau M.J., Velthuis H.H.W. (1989) Ovarian development and egg laying in workers of Bombus terrestris, Entomol. Exp. Appl. 51, 199-213.

Duchateau M.J., Velthuis H.H.W., Boomsma J.J. (2004) Sex ratio variation in the bumblebee Bombus terrestris, Behav. Ecol. 15, 71-82. 
Endler A., Liebig J., Schmitt T., Parker J.E., Jones G.R., Schreier P., Hölldobler B. (2004) Surface hydrocarbons of queen eggs regulate worker reproduction in a social insect, Proc. Natl Acad. Sci. (USA) 101, 2945-2950.

Kukuk P.F. (1992) Cannibalism in social bees, in: Elgar M.A., Crespi B.J. (Eds), Cannibalism: ecology and evolution among diverse taxa, Oxford University Press, Oxford, pp. 214-237.

Lopez-Vaamonde C., Koning J.W., Jordan W.C., Bourke A.F.G. (2003) No evidence that reproductive bumblebee workers reduce the production of new queens, Anim. Behav. 66, 577-584.

Naumann K., Winston M.L., Slessor K.N., Prestwich G.D., Webster F.X. (1991) Production and transmission of honey-bee queen (Apis mellifera L) mandibular gland pheromone, Behav. Ecol. Sociobiol. 29, 321-332.

Pereboom J.J.M. (2000) The composition of larval food and the significance of exocrine secretions in the bumblebee Bombus terrestris, Insect. Soc. 47 , 11-20.
Pereboom J.J.M., Velthuis H.H.W., Duchateau M.J. (2003) The organisation of larval feeding in bumblebees (Hymenoptera, Apidae) and its significance to caste differentiation, Insect. Soc. 50, $127-$ 133.

Ribeiro M.F., Velthuis H.H.W., Duchateau M.J., Van der Tweel I. (1999) Feeding frequency and caste differentiation in Bombus terrestris larvae, Insect. Soc. 46, 306-314.

Röseler P.-F. (1970) Unterschiede in der Kastendetermination zwischen den Hummelarten Bombus hypnorum und Bombus terrestris, Z. Naturforsch. B 25, 543-548.

Röseler P.-F. (1991) Roles of morphogenetic hormones in caste polymorphism in bumble bees, in: Gupta A.P. (Ed.), Morphogenetic hormones in arthropods, Rutgers University Press, New Brunswick, pp. 384-399.

Seeley T.D. (1985) Honeybee ecology, Princeton University Press, Princeton. 